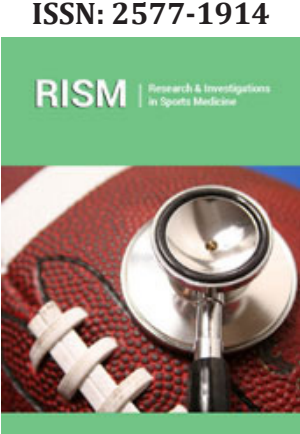

*Corresponding author: S Andrew C, University of Texas at Tyler, USA

Submission: 海July 01, 2020

Published: 侮 August 18, 2020

Volume 6 - Issue 5

How to cite this article: S Andrew $C$, Brandon W, David M, Diana G, Warner L, Julie G. Attitudes Toward and Usage of Face Masks or Face Coverings Among Certified Athletic Trainers During the COVID-19 Pandemic. Res Inves Sports Med, 6(5): RISM.000649. 2020. DOI: 10.31031/RISM.2020.06.000649

Copyright@ S Andrew C, This article is distributed under the terms of the Creative Commons Attribution 4.0 International License, which permits unrestricted use and redistribution provided that the original author and source are credited.

\section{Attitudes Toward and Usage of Face Masks or Face Coverings Among Certified Athletic Trainers During the COVID-19 Pandemic}

\author{
S Andrew $\mathrm{C}^{1,2 *}$, Brandon $\mathrm{W}^{2,3}$, David $\mathbf{M}^{3}$, Diana $\mathrm{G}^{1}$, Lynzi $\mathbf{W}^{4}$ and Julie $\mathrm{G}^{5}$ \\ ${ }^{1}$ University of Texas at Tyler, USA \\ ${ }^{2}$ University of North Carolina, Greensboro, USA \\ ${ }^{3}$ Grand Canyon University, USA \\ ${ }^{4}$ MVP Orthopedics, USA \\ ${ }^{5}$ Collin College, USA
}

\begin{abstract}
Following the widespread transmission of severe acute respiratory syndrome coronavirus 2 (SARSCoV-2), the majority of colleges and high schools canceled all face-to-face courses and athletic activities. As institutions allowed for athletes to return to campus, many institutions and government entities enacted requirements for the use of face masks or face coverings in public. Current research is being conducted to evaluate the epidemiology, recognition, treatment, and prevention of coronavirus disease 2019 (COVID-19), the disease associated with SARS-CoV-2. At the time of this study, there is no published research on attitudes toward and usage of face masks or face coverings among certified athletic trainers during the COVID-19 pandemic. The purpose of this study was to describe these attitudes toward face masks or face coverings and usage in this context. A total of 265 certified athletic trainers participated in this study (age $=42 \pm 12$, years of certified experience $=18 \pm 11$ ). An electronic survey was sent to these participants via email to collect demographic information and assess their attitudes toward and usage of face masks or face coverings. Data was downloaded and analyzed using a commercially available statistics package. The overwhelming majority of certified athletic trainers in this study, agreed on some level, the use of face masks to mitigate the transmission of SARS-CoV2 was strongly supported by the available evidence (Strongly Agree $=55.8 \%$, Agree $=26.4 \%$, Somewhat Agree $=9.4 \%$ ). Most athletic trainers also reported that their institutions currently had mandates in place requiring face masks during patient encounters and coworker interactions (Patient Encounters $=66.4 \%$, Coworker Interactions $=57.4 \%$ ). Most athletic trainers reported wearing face masks the majority of the time when entering public spaces outside of work. Athletic trainers cited influence of their personal use of face masks, was for personal health, health of those in their household, and attempting to be a role model of best practices for public health. The findings of this study suggest a majority of athletic trainers are wearing face masks or face coverings, even when not actively involved in patient care or other aspects of their jobs
\end{abstract}

\section{Introduction}

Coronavirus disease 2019 (COVID-19) is a serious respiratory disease caused by severe acute respiratory syndrome coronavirus 2 (SARS-CoV-2) [1]. COVID-19 was first reported in late 2019 in Wuhan, China [1]. The disease has shown to be highly infectious and features symptoms such as fever, dry cough, fatigue, loss of smell, loss of taste, muscle and joint pain, shortness of breath, nausea, vomiting, and diarrhea [1]. In severe cases, patients have developed potentially fatal pneumonia, septic shock, metabolic acidosis, and coagulation dysfunction [2]. In the absence of a proven treatment or vaccine, the primary recommendations to mitigate the spread of COVID-19 have been social distancing, recognition through testing, contact tracing, enhanced hygiene precautions, and face coverings [3-6].

As the global COVID-19 pandemic progressed, many communities and organizations enacted legislation and rulings to decrease the transmission of COVID-19. To this end, the National Collegiate Athletic Association (NCAA) chose to cancel all remaining spring and winter championships [7]. After this decision was made, the majority of institutions and 
conferences chose to cancel the remainder of their seasons [8]. In addition to cancellations at higher education institutions, secondary schools also postponed or suspended athletic activities for the remainder of the 2020 spring semester [9]. Not only were athletic activities canceled, the majority of higher education institutions and secondary schools in the United States cancelled face-to-face instruction $[10,11]$. As institutions and communities began to reopen following closures, rules requiring the use of face masks or face coverings were enacted in many areas [12-15]. However, some communities have thus far chosen to leave the use of face masks to individual choice $[5,6]$.

Currently, research is being conducted to evaluate the epidemiology, recognition, treatment and prevention of COVID-19 [1-4]. At the time of this study there is no published research on the attitudes toward and usage of face masks among certified athletic trainers during the COVID-19 pandemic. Therefore, the purpose of the present study was to describe the attitudes toward and usage of face masks among certified athletic trainers during the COVID-19 pandemic.

\section{Methods}

\section{Design}

This study was conducted using a cross-sectional design utilizing an internet-based survey for data collection.

\section{Participants}

Participants were recruited for this study by emailing the head athletic trainers at NCAA Division I, Division II, and Division III institutions, Commission on Accreditation of Athletic Training Education (CAATE) accredited program directors, and memberships of several regional and local athletic training organizations. These individuals were asked to send the survey invitation to any fellow staff members or preceptors associated with their programs. A total of 223 participants (age $=42 \pm 12$, years of certified experience $=18 \pm 11$ ) opened the survey link and completed the instrument. Demographic information for participants is presented in Table 1. All participants were informed of the survey's purpose and informed consent was obtained.

Table 1: Totals and percentages for participant demographic information.

\begin{tabular}{|c|c|c|}
\hline Demographic Factor & Criteria & Responses \\
\hline Sex & $\begin{array}{c}\text { Female } \\
\text { Male } \\
\text { Prefer not to answer }\end{array}$ & $\begin{array}{c}111,49.8 \% \\
111,49.8 \% \\
1,0.4 \%\end{array}$ \\
\hline Clinical Practice Setting & $\begin{array}{l}\text { College/University } \\
\text { Secondary School } \\
\text { Clinic/Hospital } \\
\text { Emerging Settings } \\
\text { Professional Sports }\end{array}$ & $\begin{array}{c}199,89.2 \% \\
15,6.7 \% \\
7,3.1 \% \\
1,0.5 \% \\
1,0.5 \%\end{array}$ \\
\hline 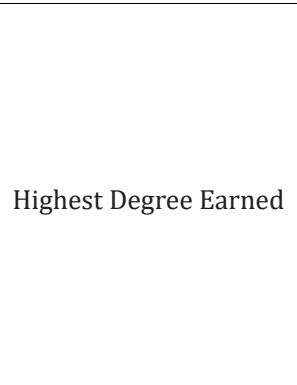 & $\begin{array}{c}\text { Professional Bachelor's } \\
\text { Professional Master's } \\
\text { Post-Professional Masters (in Athletic Training) } \\
\text { Post-Professional Master's (not in Athletic Training) } \\
\text { Post-Professional Clinical Doctorate } \\
\text { Academic Doctorate }\end{array}$ & $\begin{array}{c}26,11.7 \% \\
47,21.1 \% \\
29,13 \% \\
86,38.6 \% \\
30,13.5 \% \\
5,2.2 \%\end{array}$ \\
\hline
\end{tabular}

\section{Data collection}

An email was sent to head athletics trainers and CAATE accredited program directors at colleges and universities. These individuals were asked to complete the survey and forward the message to any fellow athletic training staff members or preceptors they work with. Survey invitations were also sent out through several regional athletic training organizations in an attempt to collect the most responses possible. The email included an invitation to participate in an electronic survey via a link from a web-based survey company (Qualtrics Inc., Provo, UT) in July 2020.
The initial message included information about the investigators, the purpose of the study, the purpose of the survey, and also informed the participants that they could opt out of the survey at any time.

\section{Instrument}

Following the demographics section, the survey contained questions regarding the participants' practice settings and whether the participant had returned to work after a COVID-19 pandemic stay at home order. The participants were also asked whether they were subject to any institutional or government mandates 
to wear face masks at work or in public. Other questions gathered information on the attitudes of participants toward wearing face masks, how often they wore face masks outside of work while in public, and what their primary considerations were when deciding whether to wear face masks.

The survey consisted of 18 questions in total. These questions included: one question regarding consent to participate in the study, two fill in the blank and three multiple choice questions regarding demographic information, 10 multiple choice questions regarding attitudes and usage of face masks at work and in public, and two ranking questions regarding considerations for whether or not to wear a facemask.

\section{Statistical analysis}

The information from participant responses was downloaded and analyzed using a commercially available statistics package (SPSS Version 26, IBM, Armonk, NY). A total of 265 athletic trainers responded, consented, and completed the study. All 265 responses were included in the data analysis. Measures of central tendency (means, standard deviations, frequencies) were calculated where appropriate.

\section{Results}

\section{Attitudes toward the use of face masks or face coverings}

The majority of responding athletic trainers agreed, at least to some extent that the use of face masks or face coverings to mitigate the spread of COVID-19 was strongly supported by the available evidence. More respondents reported considering personal and community safety rather than concerns about the perceptions of others or having their liberties infringed upon when deciding whether or not to wear a mask in public. Table 2 provides a breakdown of the questions that gathered information on respondents' attitudes toward the use of face masks or face coverings in public.

Table 2: Responses for questions on the attitudes toward the use of facemasks or face coverings in public.

\begin{tabular}{|c|c|}
\hline Statement & Most Common Responses (\%) \\
\hline $\begin{array}{l}\text { The current available evidence strongly supports the use of facemasks or face } \\
\text { coverings when interacting with others to decrease the transmission of COVID-19. }\end{array}$ & $\begin{array}{l}\text { Strongly Agree, } 128 \text { (57.4\%) } \\
\text { Agree, } 55(24.7 \%) \\
\text { Somewhat Agree, } 23(10.3 \%)\end{array}$ \\
\hline $\begin{array}{l}\text { I feel safer/would feel safer if my institution required facemasks or face coverings } \\
\text { at work. }\end{array}$ & $\begin{array}{l}\text { Strongly Agree, } 124(55.6 \%) \\
\text { Agree, } 42(18.8 \%) \\
\text { Somewhat Agree, } 18(8.1 \%)\end{array}$ \\
\hline $\begin{array}{l}\text { I feel safer/would feel safer if my local or state government required facemasks or } \\
\text { face coverings in public. }\end{array}$ & $\begin{array}{c}\text { Strongly Agree, } 119(53.4 \%) \\
\text { Agree, } 43(19.3 \%) \\
\text { Somewhat, } 16(7.2 \%)\end{array}$ \\
\hline $\begin{array}{l}\text { I would prefer that wearing facemasks or coverings be left to individual responsi- } \\
\text { bility rather than to a mandate from my institution. }\end{array}$ & $\begin{array}{c}\text { Strongly Disagree, } 83(37.2 \%) \\
\text { Disagree, } 61(27.4 \%) \\
\text { Agree, } 22(9.9 \%)\end{array}$ \\
\hline $\begin{array}{l}\text { I would prefer that wearing facemasks or coverings be left to individual responsi- } \\
\text { bility rather than to a mandate from my state or local government. }\end{array}$ & $\begin{array}{c}\text { Strongly Disagree, } 90(40.4 \%) \\
\text { Disagree, } 59(26.5 \%) \\
\text { Strongly Agree, } 19(8.5 \%\end{array}$ \\
\hline $\begin{array}{l}\text { Please rank the following considerations when deciding whether or not to wear a } \\
\text { facemask or face covering outside of work. }\end{array}$ & $\begin{array}{c}\text { Personal Safety, } 115 \text { (51.6\%) } \\
\text { Community Safety, } 84(37.7 \%) \\
\text { Being a role model of public health, } 7 \text { (3.1\%) }\end{array}$ \\
\hline $\begin{array}{l}\text { Please rank the following parties based off of how strongly you consider them } \\
\text { when deciding whether or not to wear a facemask outside of work. }\end{array}$ & $\begin{array}{l}\text { Family in your household, } 77 \text { (34.5\%) } \\
\qquad \text { Yourself, } 69(30.9 \%) \\
\text { Vulnerable populations, } 52(23.3 \%)\end{array}$ \\
\hline
\end{tabular}




\section{Face mask usage at work and in public}

Out of the responding athletic trainers, $75.4 \%$ reported that their institutions had allowed them to return to work $(n=168)$. The majority of respondents reported being required to wear face masks during patient interactions $(66.4 \%, \mathrm{n}=176)$ and during coworker interactions $(57.4 \%, \mathrm{n}=152)$. Table 3 outlines how often athletic trainers reported wearing masks in public when not at work.

Table 3: Frequency of facemask use in public when not at work among athletic trainers.

\begin{tabular}{|c|c|}
\hline Frequency & Responses \\
\hline $100 \%$ of the time & $99,44.4 \%$ \\
\hline $75 \%$ of the time & $60,26.9 \%$ \\
\hline $50 \%$ of the time & $22,9.9 \%$ \\
\hline $25 \%$ of the time & $28,12.6 \%$ \\
\hline $0 \%$ of the time & $14,6.3 \%$ \\
\hline
\end{tabular}

\section{Discussion}

The purpose of this study was to describe the attitudes of certified athletic trainers toward the use of face masks or face coverings during the COVID-19 pandemic. A secondary purpose to this study was to describe the usage of face masks among athletic trainers outside of work.

The majority of survey respondents agreed on some level that current evidence strongly supports the use of face masks or face coverings to decrease the transmission of COVID-19 (Strongly Agree $=55.8 \%$, Agree $=26.4 \%$, Somewhat Agree $=9.4 \%$ ). Furthermore, athletic trainers reported that most would feel safer if there were mandates from their institution or government requiring the use of face masks in public. This suggests that the majority of the athletic trainers surveyed feel that face masks are a useful tool for mitigating the spread of COVID-19.

Most athletic trainers reported their institutions had required or allowed them to return to work. At the institutions where athletic trainers had returned, the majority required the use of face masks during patient and coworker interactions. When not at work, most athletic trainers reported wearing face masks in public at least $75 \%$ of the time. Only $6.8 \%$ of surveyed athletic trainers reported never wearing a face mask in public. This suggests that athletic trainers are wearing face masks in public even when not at work during the COVID-19 pandemic. The most important considerations for these behaviors appear to be personal safety, household safety, and community safety.

A possible limitation of this study was the relatively low number of participants. While the total number of responses is similar or higher than other survey-based studies conducted on athletic trainers, an exhaustive and definitive statement on the attitudes and usage of face masks among athletic trainers would require a larger scale study $[16,17]$. The completion of this study provides a framework for conducting a study that collects data from a larger number of respondents.

There is a need for additional research into the attitudes, moods, and behaviors of athletic trainers and other allied healthcare professionals during the COVID-19 pandemic. One previous study investigated the moods of athletic trainers following the 2020 academic and athletic spring semester, and suggested athletic trainers were experiencing both anxiety and depression [18]. Given the athletic trainer's role in providing day-to-day patient care, it is imperative to evaluate the stresses and obstacles they are encountering due to the COVID-19 Pandemic.

\section{Conclusion}

In conclusion, the majority of surveyed athletic trainers believe the best available evidence supports the use of face masks or face coverings to decrease the transmission of COVID-19. Athletic trainers reported the majority of their institutions required face masks during patient and coworker encounters, which appeared to make them feel safer in their workspace. The majority of athletic trainers reported placing personal and community safety ahead of public perception and concerns over personal liberties being infringed upon when considering whether to wear a facemask in public. As athletic trainers, coaches, and administrators move forward, it is important to consider the best implementation and enforcement of using personal protective equipment.

\section{References}

1. Zhong BL, Luo W, Mei LH, Zhang QQ, Liu XG, et al. (2020) Knowledge, attitudes, and practices toward COVID-19 among Chinese residents during the rapid rise period of the COVID-19 outbreak: A quick online cross-sectional survey. International Journal of Biological Sciences 16(10): 1745-1752.

2. Chen N, Zhou M, Dong X, Qu J, Gong F, et al. (2020) Epidemiological and clinical characteristics of 99 cases of 2019 novel coronavirus pneumonia in Wuhan, China: A descriptive study. Lancet 395(102223): 507-513.

3. Patel R, Babady E, Theel ES, Storch GA, Pinsky BA, et al. (2020) Report from the American Society for Microbiology COVID-19 International Summit, 23 March 2020: Value of diagnostic testing for SARS-CoV-2/ COVID-19. American Society for Microbiology 11(2).

4. Ebrahim SH, Memish ZA (2020) COVID-19 - The role of mass gatherings. Travel Medicine and Infectious Disease 34: 101617.

5. Zhang R, Li Y, Zhang AL, Wang Y, Molina MJ (2020) Identifying airborne transmission as the dominant route for the spread of COVID-19. Proceeds of the National Academy of Sciences.

6. Eikenberry SE, Mancuso M, Iboi E, Phan T, Eikenberry K, et al. (2020) To mask or not to mask: Modeling the potential for face mask use by the general public to curtail the COVID-19 pandemic. Infectious Disease Modeling 5: 293-308.

7. ESPN (2020) Coronavirus cancellations and reactions in sport. 
8. ESPN (2020) SEC becomes latest conference to cancel sports for 20192020.

9. The New York Times (2020) High school sports pushed out of bounds by the pandemic.

10. CNN (2020) Universities begin considering the possibility of cancelling in person classes until 2021.

11. The New York Times (2020) As schools look for guidance, educators are left asking, 'What?'

12. California Department of Public Health (2020) Guidance for the use of face coverings.

13. KKTV (2020) New Mexico's governor requires everyone to wear a face mask in public.

14. Winston Salem Journal (2020) Face coverings now required in most campus spaces at UNCG.
15. Texas Tribune (2020) Texas' biggest public universities will require masks this fall. Enforcement will be a challenge.

16. Cage SA, Warner BJ, Gallegos DM, Fieseler C, Sims-Koenig K (2020) Characteristics of sickle cell trait policies and procedures at NCAA Division II Institutions. Research \& Investigations in Sports Medicine 6(1): 477-480.

17. Cage SA, Winkelmann ZK, Warner BJ, Gallegos DM (2020) Athletic trainers' perceived and actual knowledge of cupping therapy concepts. Journal of Sports Medicine and Allied Health Sciences 5(3).

18. Cage SA, Warner BJ, Mesman D, Warner LK, Gallegos DM, et al. (2020) Attitudes and moods among athletic trainers following suspension of 2020 athletic season. Research \& Investigations in Sports Medicine 6(3): 510-513. 